\title{
Escrita colaborativa: Bullying escolar na educação profissional técnica
}

\author{
Collaborative Writing: Scholar bullying in technical professional \\ education
}

\author{
Shirlene Bemfica de Oliveira ${ }^{1}$
}

\begin{abstract}
Resumo
Atividades colaborativas favorecem o desenvolvimento da aprendizagem e, especificamente em relação à produção escrita em língua inglesa, elas exigem dos estudantes o uso de competências linguísticas, sociais e de senso crítico, o que aumenta a necessidade de tomar decisões, de se arriscar, de compreender o outro e de resolver problemas. Além disso, elas promovem a valorização do "indivíduo" na coletividade, o aprendizado político, o empoderamento sociocultural, sentimento de pertencimento, e a possibilidade de interação social (OLIVEIRA, 2017). Por meio da colaboração, os alunos aprendem a analisar as semioses, a se posicionarem no mundo como pessoas, para a construção de identidades culturais individuais e sociais. Este trabalho é um recorte da pesquisa Escrita Colaborativa no Ensino e Aprendizagem de Língua Inglesa que busca compreender sob a ótica das teorias de ensino/aprendizagem de línguas estrangeiras, 0 impacto de tarefas escritas em coautoria no aprendizado dos alunos. Os dados foram coletados em um laboratório de ensino de línguas do Ensino Médio Técnico de um Instituto Federal por meio de produções escritas em coautoria no Google Docs, gravações em áudio e vídeo. As análises têm foco no conteúdo dos textos (BARDIN, 1977), na análise lexical e no processo de construção do gênero evidente nas interações orais para a execução da tarefa. Os resultados apontam que as atividades de produção escrita colaborativa propiciam aos alunos a oportunidade de refletir e discutir questões inerentes ao texto no que diz respeito aos assuntos, a questões de cunho crítico, político, sociolinguístico e textual. Elas promovem a autonomia, a motivação e, como resultado, os textos apresentam mais qualidade na precisão gramatical e no nível de complexidade.
\end{abstract}

Palavras-chave: Escrita Colaborativa. Língua Inglesa, Análise de Conteúdo. Padrões de interação.

\begin{abstract}
Collaborative activities favor the development of learning and specifically in relation to the written production in English, they require students to use linguistic, social and critical sense skills, which increases the need to make decisions, to take risks, to understand each other and to solve problems. In addition, they promote the valorization of the "individual" in the community, political learning, socio-cultural empowerment, feeling of belonging, the possibility of social interaction (OLIVEIRA, 2017). Through collaboration, students learn to analyze semiosis, to place themselves in the world as people, for the construction of individual, social and cultural identities. This work is an excerpt from the research "Collaborative Writing in English Language Teaching and Learning" that seeks to understand, from the perspective of foreign language teaching / learning theories, the impact of written tasks in co-authorship on students' learning. The data were collected in a language teaching laboratory at the Technical High School of a Federal Institute through written productions in co-authorship, audio and video recordings. The analysis focus on the content of the texts (BARDIN, 2009), on the lexical analysis and on the gender construction process evident in the oral interactions for the execution of the task. The results show that the collaborative writing production activities provide students with the opportunity to reflect and discuss issues inherent to the text with regard to subjects, issues of a critical, political, sociolinguistic and textual nature. They promote autonomy, motivation and, as a result, texts have more quality in grammatical accuracy and in the level of complexity.
\end{abstract}

Keywords: Collaborative writing. English Language. Content analysis. Interaction Patterns.

\section{Introdução}

1 Doutora em Linguística Aplicada. Instituto Federal de Educação, Ciência e Tecnologia de Minas Gerais, Ouro Preto, Minas Gerais, Brasil. Orcid: https://orcid.org/0000-0003-1435-1728. E-mail: shirlene.o@ifmg.edu.br

LínguaTec, Instituto Federal de Educação, Ciência e Tecnologia do Rio Grande do Sul, Bento Gonçalves v. 5 , n. 2, p.23-45, nov. 2020. 
Neste trabalho, o ensino de línguas estrangeiras na Educação Profissional Técnica é pautado pelo desenvolvimento das habilidades de compreensão e produção oral e escrita de forma integrada com o uso das tecnologias, dentro de uma abordagem de Multiletramentos, o que transcende a visão de ensino compartimentalizada (BOTELHO, 2012; STREET, 2014). Na prática, ela se desenvolve no âmbito da formação omnilateral, do letramento sociocultural, considerando o desenvolvimento da competência comunicativa nos âmbitos operacionais (saber como fazer), culturais (saber interagir com o outro), críticos (saber ver a língua como um instrumento de poder) e tecnológicos (utilizar-se das ferramentas para interagir e desenvolver a interlíngua) (LANKSHEAR, BIGUM et al., 1997; LEFFA, 2011). Para além do ensino linguístico, apontamos algumas implicações dessa perspectiva crítica: nas concepções de língua; na abordagem de ensinar de forma reflexiva; nos valores sociais, éticos e políticos reconstruídos por meio do ensino da língua; nas formas de identidade e subjetividade que encorajam, melhoram e/ou permitem a mediação das relações humanas e sociais (LEFFA, 2011). Tomamos como ponto de partida, a consciência da abordagem de aprender do aluno, aliando teoria e prática, para possibilitar ações para a transformação dos papeis assumidos pelos participantes no contexto escolar como um ambiente propício ao letramento crítico. Nesse sentido, esse contexto pode favorecer os alunos, pois eles podem aprender a se posicionar no mundo como pessoas, para a (re)construção de suas identidades culturais individuais e sociais. Ademais, a língua ensinada nessa perspectiva interdisciplinar e crítica pode ser uma ferramenta de mudança da sociedade, principalmente no que concerne ao seu ponto de vista humano, um meio de aprendizado político, no qual os alunos podem questionar as relações sociais, podem desafiar a ideologia dominante, se comprometer com a justiça social, desenvolver a autonomia e o empoderamento sociocultural, conhecendo e valorizando a ascensão de grupos sociais diversos (OLIVEIRA, 2017).

O projeto de pesquisa "Escrita Colaborativa no Ensino e Aprendizagem de Línguas Estrangeiras" tem como objetivo promover momentos para que alunos possam ler, discutir e escrever sobre assuntos diversos gêneros textuais na língua alvo em coautoria, além de analisar o impacto dessas atividades feitas em pares e trios na aprendizagem dos alunos iniciantes e de nível intermediário. Ele se pauta na concepção de aprendizagem cooperativa e dos Multiletramentos. A metodologia utilizada se justifica, pois estudos recentes apontam que as atividades em pares e grupo desenvolvidas em sala de aula ou na modalidade online podem ser benéficas aos alunos em termos do desenvolvimento linguístico, cognitivo e social. Especificamente em relação à produção escrita em língua inglesa, essas atividades ajudam a diminuir a ansiedade relacionada ao processo de produção textual, aumentam a autoconfiança dos alunos, facilitam e melhoram a interação (SHEHADEH, 2011; 
STORCH, 2005; SWAIN, 2010). Além disso, as tarefas de escrita colaborativa exigem dos estudantes o uso de competências sociais, o que aumenta a necessidade de tomar decisões, de se arriscar, de tolerar o outro e de resolver problemas. Quando bem planejadas, as atividades de produção escrita colaborativa promovem a autonomia, a motivação e, como resultado, os textos apresentam mais qualidade na precisão gramatical e no nível de complexidade.

Para esse recorte, os dados foram coletados com oito alunos em um laboratório de ensino de línguas do ensino médio técnico do Instituto Federal Minas Gerais e por meio de tarefas de produção escrita em língua inglesa com o uso do Google Docs², gravações em vídeo e áudio. A investigação foi orientada pelo conteúdo dos textos e pelo processo da produção escrita evidente nas análises das interações orais para a execução da tarefa. As análises foram feitas com 0 uso do concordanciador textual, o Iramuteq, que auxilia no cálculo estatístico com ênfase na frequência, na riqueza lexical dos textos (FINATTO, et al., 1999), a natureza da linguagem, bem como as representações sociais da temática construídas nos textos.

\section{Contexto metodológico da pesquisa}

Este artigo é um recorte da pesquisa Escrita colaborativa no ensino e aprendizagem de língua inglesa registrada pela Diretoria de Inovação, Pesquisa e Extensão de um campus do Instituto Federal no Estado de Minas Gerais ${ }^{3}$. Os participantes foram 8 alunos de segundo ano de língua inglesa do ensino médio técnico advindos de cursos de Metalurgia, Mineração e Edificações (nível préintermediário de Língua Inglesa). Nesse projeto, os alunos se encontravam semanalmente para selecionar temas para discussão, leitura e escrita de textos em inglês e a problemática do Bullying foi escolhida dentre outras produções escritas para esse artigo devido a sua importância atual.

No projeto, os textos são produzidos individualmente, em pares ou em trios, dependendo da programação. Durante a elaboração dos textos colaborativos, os alunos escolhem seus parceiros por afinidade e esses interagem na língua inglesa ou na língua materna, como desejarem. Os encontros são gravados com o auxílio de uma webcam, de gravadores de celulares e duram cerca de 1 hora e 30 minutos. Esses alunos já são familiarizados uns com os outros, pois são também os bolsistas PIBIC Jr.

\footnotetext{
2 Google Docs é um pacote de aplicativos do Google usado nesse projeto para a escrita, edição e para a portabilidade de textos por mais de um usuário.

3 O projeto foi submetido a um edital de fomento interno e passou pelo CEP UFOP/Ouro Preto. Os pais receberam e assinaram os termos de assentimentos autorizando a participação dos alunos na pesquisa, o uso de imagem, das transcrições das gravações e dos textos produzidos.
} 
dos projetos de língua inglesa, e na ocasião, foram autorizados pelos pais a participarem da pesquisa por meio da assinatura dos termos de assentimento.

As discussões para a produção dos textos sobre bullying foram gravadas em áudio e vídeo, transcritas e geraram os dados que foram analisados com base nos padrões de colaboração. As análises foram feitas com o auxílio do software e concordanciador Iramuteq, o que permitiu entender os textos na coletividade. As grelhas de análises serão detalhadas a seguir.

\subsection{Iramuteq: software de análise textual}

De acordo com Camargos e Justus (2013, p. 1), o software Iramuteq (Interface de R pour les Esterlyses Multidimensionnelles de Textes et de Questionnaires) é gratuito, com fonte aberta e permite fazer análises estatísticas sobre corpora textuais, textos individuais e palavras. Ele ancora-se na interface $\mathrm{R}$ e na linguagem $P$ ython ${ }^{4}$. A imagem abaixo é a reprodução da abertura do Iramuteq.

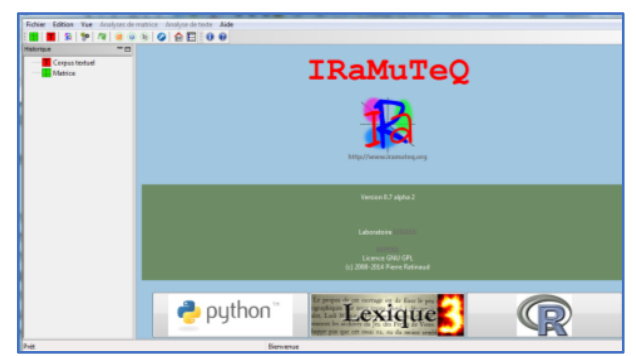

Figura 1: Interface do Iramuteq

Fonte: http://www.iramuteq.org/captures-decrans/interface/home-0-7-alpha-2

Assim como outros concordanciadores usados pela Linguística de Corpus, o Iramuteq permite a investigação das especificidades a partir da segmentação definida do texto, transformando unidades de contexto iniciais em unidades de contexto elementares (CAMARGOS; JUSTUS, 2013). De acordo com os autores, o software identifica a quantidade de palavras, a frequência média e o número de

\footnotetext{
4 Iramuteq disponível em http://www.iramuteq.org/ R: www.r-project.org Python www.python.org
} 
hapax ${ }^{5}$ (formas de frequência um); pesquisa o vocabulário e reduz as palavras com base em suas raízes (lematização6); cria dicionário de formas reduzidas, identifica formas ativas e suplementares.

O Iramuteq ainda faz a análise de contraste de modalidades de variáveis, a classificação hierárquica descendente (CHD), conforme o método descrito por Reinert (1990), análise de similitude de palavras presentes no texto, e faz a construção de dendogramas e nuvens de palavras com similitude semântica. Nesse caso, os segmentos de texto são classificados em função dos seus respectivos vocabulários, e o conjunto deles é repartido em função da frequência das formas reduzidas, ou seja, em campos semânticos (CAMARGO; JUSTUS, 2013). Essa análise visa obter classes de segmentos de texto que, ao mesmo tempo, apresentam vocabulário semelhante entre si, e vocabulário diferente dos segmentos de texto das outras classes (CAMARGO; JUSTUS, 2013). A partir dessas análises em matrizes, o software organiza a análise dos dados, ilustra as relações entre as classes, executa cálculos e fornece resultados, o que nos permite a descrição de cada uma das classes, principalmente, pelo seu vocabulário característico (léxico) e pelas suas palavras com asterisco (variáveis) em textos individuais e/ou em um conjunto de textos.

Além disso, segundo Camargo e Justus (2013), o programa apresenta a análise fatorial de correspondência feita a partir da classificação hierárquica descendente (CHD). Com base nas classes escolhidas, o programa calcula e fornece-nos os segmentos de texto mais característicos de cada classe (corpus em cor) permitindo a contextualização do vocabulário típico de cada classe. Os autores afirmam que em nível do programa informático, cada classe é composta de vários segmentos de texto em função de uma classificação segundo a distribuição do vocabulário (formas) destes segmentos de texto. O Iramuteq se vale de cálculos sobre as coocorrências de palavras em segmentos de textos construídos a partir do corpus para listar e apresentar as formas reduzidas mais frequentes por meio de listas, gráficos, dendogramas e nuvem de palavras. A análise conjugada permite compreender a relação "entre contexto linguístico e representação coletiva", ou seja, maneiras coletivas de pensar sobre determinado assunto por um determinado grupo de pessoas (REINERT, 1990).

\footnotetext{
5 Hapax: "Em qualquer corpus, as formas de frequência 1 (também conhecidas como 'hapax legomena') são a maioria. Baseando-se neste fato, é possivel afirmar que o léxico de frequência baixa é o mais comum, isto é, que a maioria das palavras de uma língua é composta de palavras que ocorrem poucas vezes. Em outras palavras, palavras de baixa frequência têm uma probabilidade baixa de ocorrência (1 em 1 milhão, por exemplo) e, já que elas formam a maior parte do vocabulário de uma língua, é necessário usar amostras grandes para que tais palavras possam ocorrer" (BERBERSARDINHA, 2000, p. 344).

${ }^{6}$ Lematização: "A lematização é uma técnica geralmente utilizada por buscador de palavras em sites para abranger a quantidade de opções de palavras relacionadas com a palavra procurada, ignorando o tempo verbal, caso seja um verbo, 0 gênero da palavra, o plural etc." (FERNANDES, 2014, p. 10).
} 
A seguir serão apresentadas as metodologias de análise das interações que focam nas formas de estabelecer os diálogos, nas características das colaborações e nos episódios relacionados à linguagem utilizados para a discussão linguística dos textos.

\subsection{Análise da interação: Padrões de Colaboração}

Nesta pesquisa, a unidade e análise é o grupo, ou seja, procuramos entender as variáveis que interferem na mediação e negociação para a construção dos textos na coletividade por meio da colaboração. Para a compreensão dos conceitos de colaboração, partimos dos trabalhos de Mercer (1992) e Bolzan (2015, 2016), que analisaram alunos em interação e identificaram três formas de estabelecer o diálogo: a fala disputacional, a fala cumulativa e a fala exploratória. Segundo as autoras, a fala disputacional é caracterizada pelo desacordo constante entre os falantes e a tomada de decisões individualizada. Nesse modelo, um parceiro não aceita a opinião do outro. Na fala cumulativa, os falantes constroem o diálogo positivamente, todos opinam, mas não se posicionam criticamente em relação ao que foi dito pelo outro, gerando cooperação. Finalmente, na fala exploratória, em que os parceiros se engajam criticamente e construtivamente com as ideias uns dos outros e as afirmações e sugestões são oferecidas para consideração conjunta, gerando colaboração.

Além desses modos de interação, Ballinger (2013) classificou os movimentos da interação de acordo com a ocorrência ou não de conflitos. De acordo com a autora, nas interações em que não ocorrem conflitos, pode haver aceitação, reconhecimento e elaboração das contribuições recebidas, além da confirmação do entendimento do outro. Já nas interações conflitivas, não há a confirmação do entendimento do outro, podem ocorrer falas em desrespeito às habilidades linguísticas dos parceiros, à rejeição, à negligência e/ou à disputa pelo feedback.

Os modos de interação em consonância com a existência ou não de conflitos podem desencadear desde relações de dominação até interações bem colaborativas, o que interfere no processo de escrita e no texto final. Storch $(2005,2009 ; 2013)$ investigou interações de alunos escrevendo em pares e verificou a existência de padrões de colaboração, cooperação, de ensino, de dominação e passividade durante as produções. Ela propôs a análise da interação em pares com dois contínuos de igualdade e mutualidade. Nesse modelo, a igualdade, na linha contínua horizontal reflete o nível de contribuição e controle do aprendiz sobre a língua alvo e sobre a tarefa (as contribuições, as decisões e a relação colaborativa). Dessa forma, a igualdade alta descreve não só as contribuições em nível de igualdade, mas também igualdade nas tomadas de decisões e de percepção de autoridade sobre a língua e sobre a tarefa (STORCH, 2013, p. 61). A mutualidade, na linha contínua vertical, indica 
o nível de engajamento com as contribuições do outro, ou seja, as evidências de co-construção. A mutualidade alta descreve interações que mostram evidências de co-construção e que são ricas em feedback recíproco. Com isso, as duas linhas de igualdade e mutualidade formam quatro quadrantes que representam padrões distintos de interação diádica, que serão apresentados a seguir:

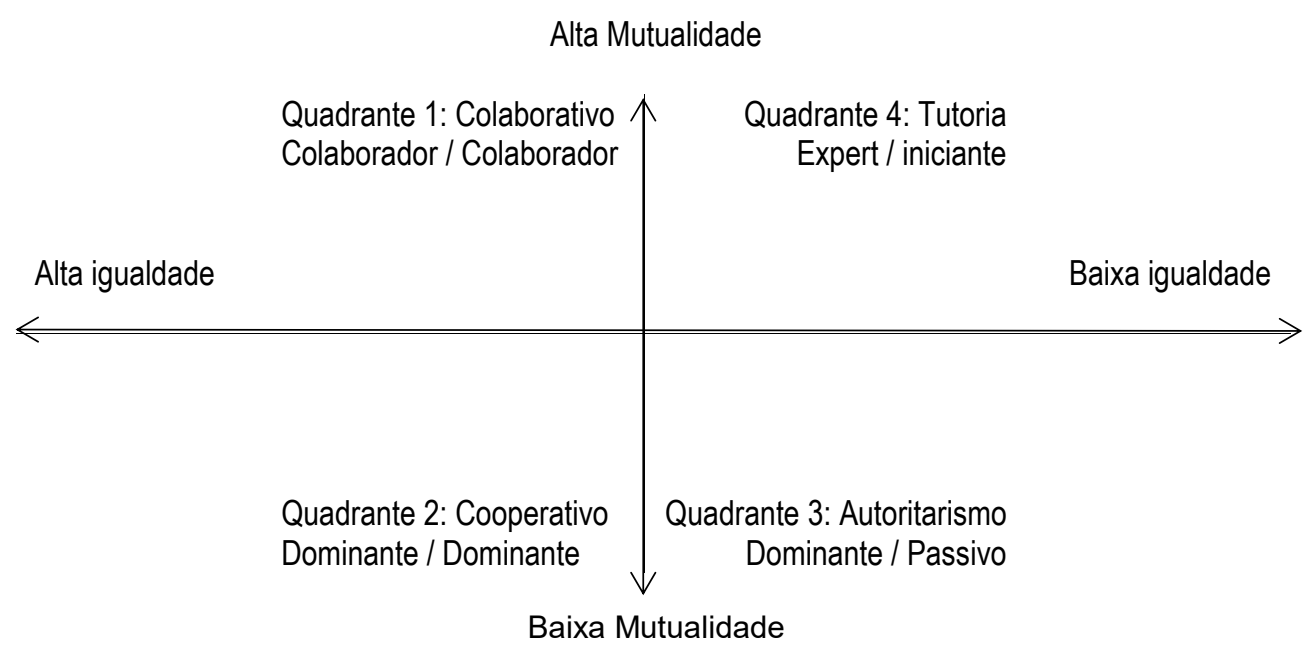

Figura 2: Modelo de interação em pares

Fonte: Adaptado de Storch (2013, p. 62)

O quadrante 1, representa dois alunos participando da tarefa escrita com colaboração, o que envolve um esforço coordenado do par para completar a tarefa juntos. Na escrita em pares, os papeis e contribuições para a criação dos textos não são divididos. Ao invés disso, há um engajamento mútuo e esforço coordenado por todos os membros do par ou grupo no processo de composição (STORCH, 2005 , p. 3). Ambos os membros contribuem em todos os aspectos da tarefa e se engajam aceitando as sugestões uns dos outros, com frequência centralizam nos recursos linguísticos e promovem andaimes coletivos para resolver as deliberações sobre a linguagem (STORCH, 2005, p. 61). Dillenbourg et al. (1996, p. 2) afirma que na colaboração, os processos cognitivos podem ser heterarquicamente divididos em camadas interligadas e inter-relacionadas.

No quadrante dois, os dois alunos estabelecem uma relação de cooperação. Pelas setas da figura 2, observa-se que a igualdade é alta, a mutualidade é baixa, pois ambos os componentes têm competência linguística e condições de contribuir na tarefa, mas não se engajam ou não querem se engajar aceitando as contribuições de forma mútua. A cooperação se configura, pois segundo Dillenbourg et al. (1996), esses alunos dividem o trabalho entre eles para completar a tarefa. Durante a tomada de decisão, há um alto nível de conflito (geralmente conflito negativo) e, de acordo com Storch 
(2013, p. 62), os textos produzidos com o predomínio deste padrão de interação são fragmentados como se fossem dois textos paralelos, pois cada um faz uma parte.

No quadrante 3 , temos uma dupla de alunos, provavelmente um mais proficiente do que 0 outro. Nessa configuração, um parceiro é dominante e outro passivo, o que torna a igualdade e a mutualidade baixa. A relação é estabelecida por dominação, pois um membro do par, o mais proficiente, toma o controle da tarefa ou é concedido a ele o controle da tarefa e o outro membro contribui muito pouco. A relação estabelecida é de autoritarismo, pois o parceiro mais proficiente controla a atividade e a participação do outro aluno é mínima. Geralmente, ele somente escreve o que 0 outro determina.

Por fim, a relação estabelecida no quadrante 4 , quando um aluno sabe muito e ensina ao iniciante. Nessa interação, a igualdade é baixa, mas a mutualidade é alta, o que configura um nível desigual de contribuição e de controle sobre a tarefa. No entanto, o que distingue esse padrão do dominante / passivo é que nesse padrão, o participante dominante, geralmente mais proficiente, age como um especialista, um expert ou tutor e ativamente encoraja o outro participante menos experiente a contribuir com a tarefa, diferentemente do quadrante 3 em que o dominante é autoritário.

É importante mencionar que é possível encontrar mais de uma dessas configurações durante as produções de textos colaborativos, pois a distribuição ou delimitação dos papeis muda rápido, dependendo da natureza da tarefa e da interação construída. No entanto, a predominância de uma delas no par pode ter impacto no processo de produção escrita e no produto textual (STORCH, 2013). Dessa forma, esse tipo de análise se mostra relevante para entender o processo de andaimento (scaffolding), no qual um aluno mais proficiente ou experiente pode auxiliar 0 iniciante no desenvolvimento de sua aprendizagem. Além disso, mostra que a colaboração que afeta a $Z D P^{7} \mathrm{e}$ promove andaimento, "requer que os membros de um grupo respeitem as perspectivas uns dos outros e confiem na opinião uns dos outros, o que pode ser difícil de alcançar se a diferença entre as proficiências for muito grande". Para a colaboração eficaz, ambos os membros devem unir seus conhecimentos linguísticos para fornecer e receber auxílio, o que configuraria o andaimento coletivo (collective scaffolding) ou mútuo (BOLZAN, 2016, p. 41).

\footnotetext{
7 ZDP: Zona de desenvolvimento proximal - No contexto escolar, a ZDP é a distância existente entre o que 0 aprendiz consegue fazer de forma independente e o que ele consegue realizar com 0 auxílio de outra pessoa em um nível de desenvolvimento mais avançado. Para Vygotsky (1991), as situações de aprendizagem vividas pelo sujeito e mediadas na interação com pessoas mais experientes geram mudanças qualitativas e impulsionam o processo de desenvolvimento. Para identificar a Zona de Desenvolvimento Proximal dos alunos é preciso que conhecer também os conceitos de desenvolvimento real, que é o conhecimento já consolidado pelo aluno, e desenvolvimento potencial, que diz respeito ao que o discente consegue realizar de forma assistida. A ZDP é o intervalo entre esses dois níveis de desenvolvimento (VYGOTSKY, 1991; SOUZA; ROSSO, 2011).
} 


\section{Resultados e discussão}

Para o desenvolvimento da pesquisa, dividimos as análises em três partes: primeiro analisamos as escolhas lexicais do grupo de alunos do ensino médio técnico para os textos sobre bullying com o Iramuteq; a construção temática do grupo e, em seguida, a análise da interação promovida, considerando os turnos e os episódios nos quais os alunos discutem para escrever os textos.

\subsection{Análises das produções de texto enquanto corpus}

Para a análise lexical, as produções de texto foram entendidas enquanto representativas de grupo social na coletividade, e, para tal, contamos com o auxílio do concordanciador Iramuteq. Esse tipo de análise confirma as escolhas lexicais comuns do grupo e as semelhanças entre os textos do corpus. Para isso, o corpus foi subdividido automaticamente pelo Iramuteq, em 44 segmentos de texto sendo 1656 palavras, sendo 524 formas e 310 hapax, 59,16\% das formas e 18,72\% das ocorrências. A média de formas por segmento foi de 37, 636364 e a média de ocorrência por texto é de 414 palavras. A média de palavras no texto traz o indicador de medida de tamanho dos textos, em relação ao tempo disponível para a tarefa (1hora e 30 minutos) e o nível de proficiência dos alunos. O Iramuteq criou as listas de frequência em tabelas, apresentando o corpus subdividido em 465 lemas, 306 formas ativas, 159 formas suplementares, formas ativas com frequência menor ou igual 3:63

O entrecruzamento feito com as formas ativas ou palavras de conteúdo, mais frequentes do corpus são bully (35), school (27), problem (19), kid (16), violence (13), case (11), parent (11), student (11), person (9), victim (8), happen (7), teenager (7), family (6), society (6). Elas indicam que o bullying é um problema social principalmente relacionado às crianças e aos adolescentes no contexto escolar.

Nessa etapa, Nascimento e Menandro (2006) afirmam que o programa seleciona as formas reduzidas com frequência igual ou superior a 4 e define as Unidades de Contexto Elementar a partir da pontuação. Nessa etapa, ele realiza o cálculo de três cruzamentos: a Classificação Hierárquica Descendente - CHD que compreende todas as UCEs em relação a todas as formas reduzidas; UC tamanho 1 em relação as formas reduzidas selecionadas; e a UC tamanho 2 em relação as formas reduzidas selecionadas. As classes de 1 a 8 apresentam os seguintes itens lexicais mais frequentes que compõem a figura 3 a seguir: 
Classe 1: physical. bully, before, on, between, other, is

Classe 2: teenager, nowadays, this, who, another, in, with

Classe 3: turn, violent, society, kid, parent, problem, what, into, can, because

Classe 4: kid, person, teach, problem, be,

Classe 5: action, parent, violence, identify, aggressor, punishment, case, school

Classe 6: cause, home, victim, their

Classe 7: student, research, form, show, feel, according

Classe 8: student, create, lot, consequence, case, there

(Itens lexicais transcritos da figura 3)

Os itens lexicais acima mencionados foram agrupados pelo Iramuteq, com base no corpus dos aprendizes e relacionados em 44 segmentos de texto (UCEs). Por meio da classificação hierárquica descendente, o programa dividiu o corpus em dois subcorpora formados a partir de matrizes diferentes para cada um dos cruzamentos: classe 7 relacionada as classes 1 e 2, e classe 6 relacionada as classes 3 e 4 e classes 5 e 8 , conforme a Figura 3.

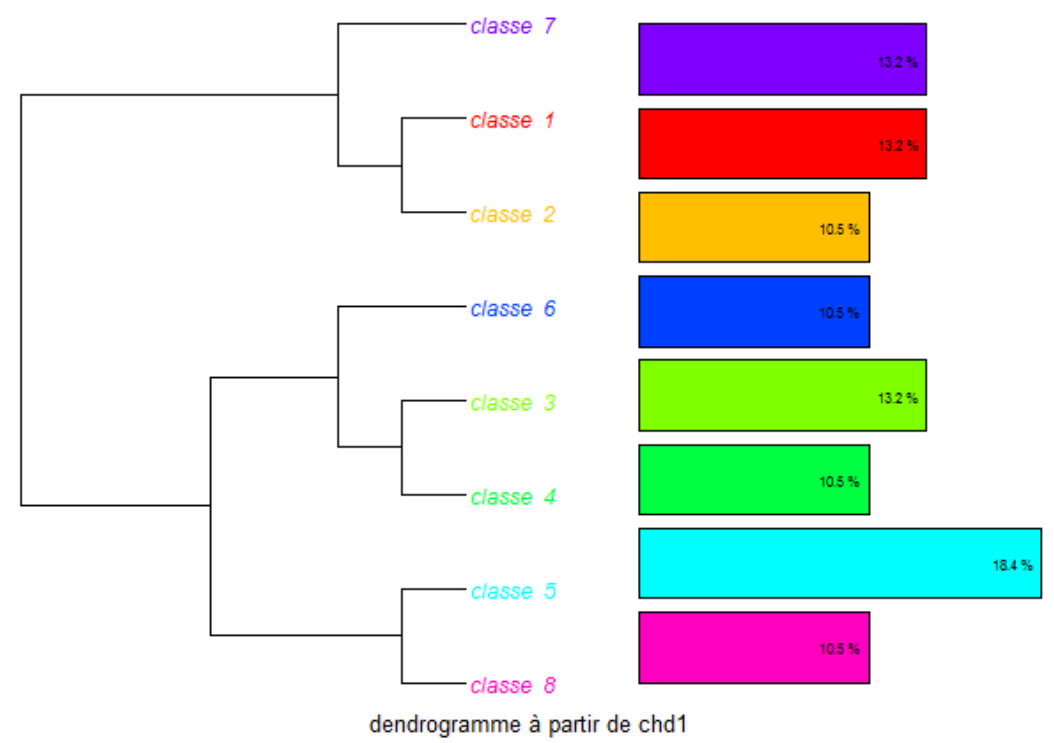

Figura 3: Dendograma das palavras mais frequentes do corpus

Fonte: Dados da pesquisa

O primeiro subcorpus, composto pela classe 1, é o conjunto total de unidades contextuais na matriz de indicadores iniciais e apresenta os pontos centrais discutidos pelos alunos em relação ao bullying com semelhança semântica em relação as outras classes. No dendograma da figura 3, é possível observar que os dois blocos formados, respectivamente pelas classes 6 e 7, são independentes. Isso quer dizer que a classe 6 tem mais relação ou proximidade com as classes 3 e 4 ou 5 e 8 e pouca ou nenhuma relação com as classes 1 e 2 . No corpus dos aprendizes, quanto mais próximos os elementos dispostos no plano, mais eles falam das mesmas coisas, por exemplo, no 
quadrante em alaranjado que representa a classe 2, o substantivo teenager que é o mais frequente e portanto maior, está mais relacionado aos vocábulos agression, form, research, physical, attack. 0 mesmo substantivo está distante dos vocábulos de outros quadrantes, por exemplo, com vocábulos tais como: consequence, parent, ou todos os itens da classe 5. Isto demonstra que foram menos relacionados nos textos do grupo mesmo pertencendo a mesma classe.

Outra análise feita com o auxílio do Iramuteq foi a análise da semelhança semântica das palavras e a representação em forma de árvore. Ela é baseada na teoria dos grafos ${ }^{8}$, e mostra as coocorrências e as conexões entre as palavras do corpus. O Iramuteq gerou a árvore semântica da relação entre os quatro textos, relacionando os agrupamentos de itens lexicais, e encontrou três grandes grupos, como mostra a figura 4 abaixo:

\footnotetext{
8 Teoria dos grafos: esse ramo da matemática estuda as relações entre os objetos de um determinado conjunto. Segundo o autor, para comprovação, são empregadas estruturas chamadas de grafos, $G(V, E)$, onde $V$ é um conjunto não vazio de objetos denominados vértices e $\mathrm{E}$ é um subconjunto de pares não ordenados de $\mathrm{V}$, chamados arestas. Lucchesi (1979) argumenta que dependendo da aplicação, arestas podem ou não ter direção, pode ser permitido ou não arestas ligarem um vértice a ele próprio e vértices e/ou arestas podem ter um peso (numérico) associado. Segundo ele, se as arestas têm uma direção associada (indicada por uma seta na representação gráfica) temos um dígrafo (grafo orientado). Um grafo com um único vértice e sem arestas é conhecido como grafo trivial. Estruturas que podem ser representadas por grafos estão em toda parte e muitos problemas de interesse prático podem ser formulados como questões sobre certos grafos. Por exemplo, no corpus de aprendizes apresentados neste artigo, a estrutura de ligações dos itens lexicais pode ser representada por um dígrafo: os vértices são os textos do corpus e existe uma aresta do texto 1 para o texto 2 se e somente se o texto 1 contém um link para $2 \mathrm{e}$ assim por diante com os outros textos. Dígrafos são também usados para representar máquinas de estado finito (LUCCHESI, 1979).
} 


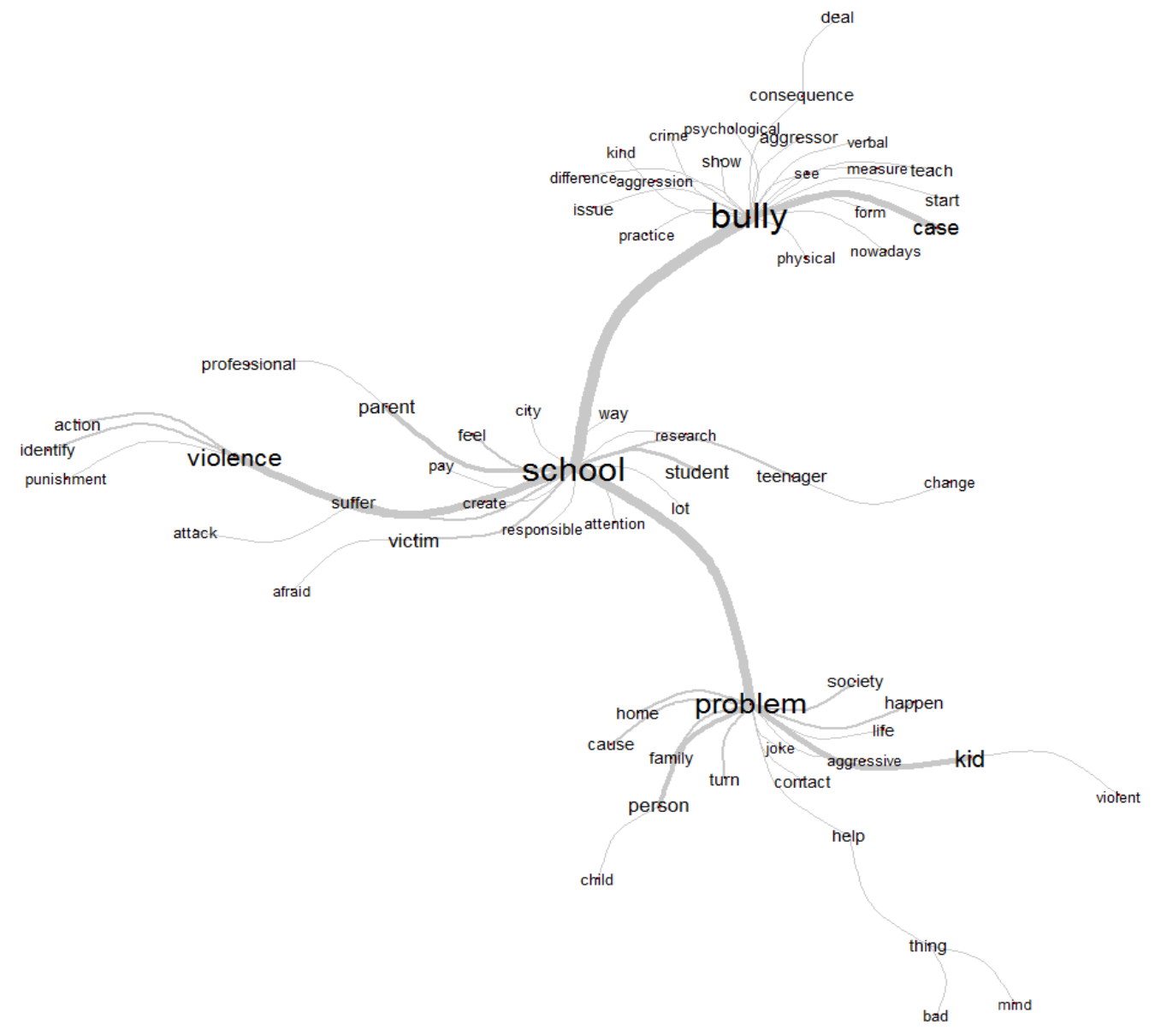

Figura 4: Análise de semelhança semântica em árvore Fonte: extraído pela autora com o auxílio do Iramuteq

O primeiro deles, correspondente ao item lexical school e itens associados, reflete um dos focos da proposta para a produção textual: o bullying no ambiente escolar. Itens como parent, professional, pay attention, change, way refletem as opiniões dos alunos em relação aos responsáveis por encontrar os meios e tomar providências sobre as ocorrências de bullying e promover mudanças. 0 item lexical violence aparece em destaque dentro desse grupo, indicando o bullying como um causador de sofrimento, potencializador da violência no ambiente escolar e relacionado ao posicionamento da comunidade escolar de conscientizar, agir e punir. Almeida Zequinão et al. (2016, p. 194) ressaltam a fragilidade de crianças e adolescentes vitimizados (teenagers), que, além de passarem pelos atos violentos, não encontram suporte e apoio necessário na escola nem por parte dos outros colegas, nem por parte dos professores e funcionários da escola. Os resultados desses autores indicaram que muitos servidores ainda são omissos perante esse comportamento violento na escola. Assim, a junção de ambientes espaçosos, mas com pouca supervisão, e crianças ociosas torna essas escolas locais auspiciosos para a prática de bullying. 
O segundo grupo tem como centro o item lexical bully, que está relacionado nos textos com a natureza do ato, as ações dos agressores, os tipos e as consequências. Esse grupo está associado ao bullying enquanto um crime, com agressões físicas e verbais, itens que demonstram a preocupação dos autores em definir o conceito de bullying, falar das formas, causas e consequências exemplificadas. $O$ terceiro grupo é centrado no item lexical problem relacionando bullying aos verbos (happens, turn, cause, help), aos substantivos (society, life, person, family, contact, joke, home) e aos adjetivos (agressive, violent). Para Almeida Zequinão et al. (2016, p. 192), os diversos tipos de bullying podem ocorrer dentro de todo 0 ambiente escolar e suas imediações, principalmente nos espaços e tempos livres dos alunos. No estudo desses autores, os atos de bullying ocorreram principalmente nas salas de aulas, nos recreios, nas aulas de Educação Física ou espaços destinados para tal e na saída da escola. A palavra life também é destacada, seguida pelas palavras crime, violence, persons and prison. As palavras mais frequentes relacionam bullying a um dos maiores problemas das escolas que segundo os alunos ocorre principalmente com as crianças menores e jovens no contexto escolar. Os textos informam que o agressor pode agir de maneiras diferentes usando desde a agressão verbal a física, ambas com consequências psicológicas. Os alunos não utilizaram itens lexicais ou construções, como a primeira pessoa do singular, que representam relação direta pessoal com a temática, estando ausentes relatos pessoais de experiência e memória.

\subsection{Análises das produções de texto: construção temática}

As análises dos textos das duplas têm foco nos processos propostos por Boccia et al. (2013), a partir do ciclo de produção dos gêneros que desencadeia na construção da temática.

1) problematização dos sentidos cristalizados pelo senso comum - essa acepção de letramento crítico sugere a adoção de práticas que possibilitem ao aluno o questionamento do status quo e posições hegemônicas;

2) questionamentos a partir de múltiplos pontos de vista - essa dimensão propõe considerar diversas perspectivas de intepretação do mundo dando visibilidade à diferença e às vozes silenciadas e/ou marginalizadas;

3) foco em aspectos sociopolíticos - a tônica dessa dimensão se atenta para as relações de poder concernentes à macro estruturas e para a não-neutralidade de linguagem e das relações sociais. Dito de outra forma, os sistemas sociopolíticos, as relações de poder e a linguagem são elementos que não podem ser dissociados e afetam as práticas políticas cotidianas, sejam elas na micro ou macroestrutura.

4) intervenção social - a última dimensão enfatiza o comprometimento e engajamento dos sujeitos em práticas sociais que visam dar voz e reconhecimento a questões relevantes para os sujeitos.

Em relação à construção temática, todas as duplas apontam o bullying como um problema escolar antigo, que tem causas sérias e as consequências que vão desde o confronto entre colegas até ao suicídio das vítimas. De acordo com os alunos, há o estabelecimento de uma relação em que eles 
podem assumir papeis diferentes: agressores, vítimas e vítimas-agressoras. 0 agressor estabelece uma relação violenta para se expressar, para se sentir superior ou simplesmente por repetir um comportamento próximo ao convívio social dele. Outros alunos enfatizaram que geralmente há uma cobrança sobre os jovens em sentirem-se responsáveis pela perfeição física e/ou comportamental ou por precisarem se encaixar em modelos pré-estabelecidos pela sociedade. No entanto, observa-se que alguns sentidos cristalizados pelo senso comum que não questionam, mas concordam com alguns posicionamentos hegemônicos, conforme o exemplo abaixo:

The cause is always connected with the family structure and their relationship with the kid. When we have single mothers or fathers, the fault of a member in the family, economic problems, violence at home, inexperience of the parents on education, most of the cases, affect the kids and the kids develop certain need and sometimes for not being prepared psychologically the kid starts to practice bullying. Because of their bad education, the kid turns into a violent person (Dupla 2) ${ }^{9}$.

Na perspectiva desses alunos, uma das possíveis causas do bullying escolar está sempre atrelada à estrutura ou formação nuclear da família, o que pode não ser verdadeiro. A desigualdade social e os casos de violência familiar talvez sejam mais adequados para explicar o comportamento violento da pessoa que comete bullying: o agressor. Por outro lado, temos a vítima: pessoa que sofre sistematicamente com a violência física, psicológica, e a exclusão. Ela tem sua vida afetada e muitas vezes o agressor não reconhece que está sendo violento, conforme nos mostram os excertos abaixo:

\begin{abstract}
All of those kinds of bullying make the victim's life a real nightmare, destroying friendships, causing problems with the family, making the kid afraid of school or even afraid of interacting with new people. Lots of kids and teenagers who suffer the attacks feel misplaced in their schools and cities and, to change this, they moved to another school or even to another city. Psychological problems are another consequence and might turn the bullying target into an aggressive person who can make murderer in the future or commit suicide (Dupla 1).

In some cases, the aggressor sees his own actions just as jokes and not as bullying and violence. But, actually, these attitudes cause impacts and traumas on the victim, such as aggressive reactions, phobias, loss of school performance and self-esteem, depression, panic syndrome, bipolarity and suicidal thoughts (Dupla 3).
\end{abstract}

Os textos revelam o que está implícito nos atos de bullying: os jovens não estão se relacionando uns com os outros de forma saudável. Eles descrevem o trajeto de uma agressão verbal que pode se tornar um problema maior com graves consequências e que pode transformar a vítima em uma vítima agressora.

De acordo com Almeida Zequinão et al. (2016, p. 184), as pessoas que sofreram vitimização na infância, em curto prazo, são mais propensas ao abandono escolar, podem ter dificuldades nas

\footnotetext{
${ }^{9}$ Todos os excertos dos textos dos alunos foram mantidos da forma como foi escrito originalmente.
} 
atividades escolares, ficar doentes ou indispostas e terem problemas com o sono. Em longo prazo, são mais propensos a sofrer de bloqueios psicológicos, e de perturbações mentais na vida adulta, tendem a ter maior dificuldade de se relacionar com os outros, pior autoestima. Além disso, tornam-se mais propensos a cometer suicídio.

Os aspectos sociopolíticos são trazidos pelos alunos em dados de pesquisas que consultaram e que mostram que como problema tem agravado no país:

\begin{abstract}
According to IBGE, in Brazil, $30 \%$ of the teenagers are involved with bullying, $20,8 \%$ of this number is composed by aggressors and the others $7,2 \%$, the minority, are victims. And, according to HBSC, forty-one of the countries in Europe and North America show that bullying becomes less frequent between older students demonstrating that maturity is a factor in this issue. (Dupla 3).

(...) according to a research from USP (University of São Paulo), it increased from $5 \%$ to $7 \%$ in Brazilian schools in the last years. The research shows us more, $20,8 \%$ of students have already practiced bullying against their colleagues. (...) As the same research pointed, the victims suffer racism, religious intolerance, homophobia, xenophobia, machismo, so, the majority part of the attacked students is formed by social minorities. (Dupla 4)
\end{abstract}

Além disso, apontam para a necessidade de conscientização dos alunos mais jovens, pois a idade e a falta de maturidade são apontadas como fatores que podem interferir nos atos violentos. Os textos dos alunos também demonstram que a violência tem relação com as pautas das minorias: racismo, intolerância, homofobia, xenofobia, machismo etc. Almeida Zequinão et al. (2016, p. 183) analisaram o perfil dos alunos que sofrem bullying escolar e encontraram resultados próximos aos relatados pelos alunos desse estudo. Segundo os autores, as vítimas são os alunos mais novos, que têm poucos amigos, são geralmente passivos, retraídos, infelizes, pouco sociáveis, inseguros, sofrem com a vergonha, medo, depressão, ansiedade e são desesperançados quanto à possibilidade de adequação ao grupo. Eles também encontraram pessoas com deficiência física e mental, com diferentes orientações sexuais e de gênero, com defeitos congênitos ou adquiridos, além de pessoas com sobrepeso.

Nos textos, os alunos fazem propostas de intervenção social com foco em três pilares: governo, escola, família. Eles propõem o preparo das escolas para que os profissionais aprendam a lidar com o problema no contexto escolar e campanhas educativas para os alunos. Eles apontaram a necessidade de políticas públicas de diminuição da desigualdade social, políticas de enfrentamento ao problema, políticas sociais de atendimento as vítimas.

The schools need to be prepared for all the cases, it's necessary to have a psychologist to treat all the kids, the violent ones and the ones that had suffered the bullying. (Dupla 1).

The govern has to make providences like in the case of economic problems or violence in home, they have to create social programs that helps the families with their bad conditions (Dupla 1). 
Measures should be taken with the bullies. According to the intensity, they should make volunteer and communitarian work in the school or in the city, pay a tax to the victim for all the problems they caused. At home, it should not be different; the parents have to punish them, too. Besides that, the bullies should make psychiatric treatment with a professional to change their position and behavior in society and lives. In more intense cases the bully must go to judicial court, take a penalty and go to jail. (Dupla 2)

Besides that, it is crucial that the parents talk to their child, consider professional assistance and offer options like moving to another school or city. If the school is the one to identify the violence, then the parents must be notified and the school must take actions as well, talking to the aggressor or to his or her parents or legal responsible, discussing punishments and ways to help, such as professional assistance. Also, the school may promote programs to advice and advertise the students about the consequences and how to deal with the issue, stimulate the students to report cases of bullying they are aware of and create rules to prevent the violence between the students. (Dupla 3).

As propostas dos alunos corroboram programas de intervenção eficazes, que devem ser planejados de acordo com as necessidades de cada grupo social. Almeida Zequinão et al. (2016) sugerem ações participativas para fortalecer a relação entre a escola, os profissionais e a comunidade com capacitações e dinâmicas para combater todos os tipos de agressão e "tentar minimizar os efeitos dos fatores de risco aos quais essas crianças estão expostas e, consequentemente, a violência na escola" (ALMEIDA ZEQUINÃO et al., 2016, p. 194).

\subsection{Análise da Interação: colaboração em pares}

Para análise da interação, foram contados os turnos e os episódios manualmente. A primeira dupla, Beatriz (304 turnos) e Carlos (262 turnos) tiveram 40 episódios de interação analisados, com um total de 566 turnos. Ester (94) e Rodolfo (103) tiveram 22 episódios analisados com um total de 197 turnos. Marcos (150) e Julio (157) tiveram 24 episódios analisados em 307 turnos. Clarice (176) e Maria (177) tiveram 10 episódios analisados com 353 turnos e a professora somente 3 turnos. Desses episódios, foram contadas as ocorrências de colaboração, cooperação de relação de dominação e passividade e de ensino. A tabela abaixo apresenta a marcação dos episódios que estabelecem as relações citadas:

\begin{tabular}{|c|c|c|c|c|}
\hline Dupla & $\begin{array}{c}\text { 1 Colaboração } \\
\text { colaborador / colaborador }\end{array}$ & $\begin{array}{c}\text { 2 Cooperação } \\
\text { dominante / dominante }\end{array}$ & $\begin{array}{c}\text { 3 Autoridade } \\
\text { dominante / passivo }\end{array}$ & $\begin{array}{c}\text { 4 Tutoria } \\
\text { expert / iniciante }\end{array}$ \\
\hline 1 Beatriz e Carlos & 24 & 7 & 6 & 3 \\
\hline 2 Ester e Rodolfo & 12 & 0 & 9 & 1 \\
\hline 3 Marcos e Júlio & 20 & 0 & 0 & 4 \\
\hline 4 Maria e Clarice & 4 & 2 & 4 & 0 \\
\hline Total de episódios & 60 & 9 & 19 & 8 \\
\hline
\end{tabular}

Tabela 1: Quadrantes de relações estabelecidas durante a interação

Fonte: dados da pesquisa

LínguaTec, Instituto Federal de Educação, Ciência e Tecnologia do Rio Grande do Sul, Bento Gonçalves v. 5, n. 2, p.23-45, nov. 2020. 
A seguir serão apresentados alguns exemplos das interações em que ocorreram colaboração, cooperação, dominação e os momentos em que um aluno toma o turno para ensinar seu parceiro (tutoria). O primeiro exemplo a seguir é da dupla 2, o qual mostra o momento em que eles elaboram a construção temática do texto assumindo ambos papeis de colaboradores. Eles procuram executar a tarefa juntos, aceitando as ideias que são compartilhadas, conforme mostra o exemplo abaixo:

\footnotetext{
Dupla 2

Rodolfo: Acho que a gente pode falar da influência da violência, né?! Que começa em casa passa para a escola e vai gerando um ciclo de violência.

Ester: Isso! Acho que a gente pode falar também que eles poderiam tipo olhar muito isso porque às vezes a criança não tem nem noção de que ela está ofendendo a outra criança.

Rodolfo: Ter um cuidado maior, né?! Verdade!

Ester: $\mathrm{E}$ aí, como é que a gente começa?

Rodolfo: Acho que pode começar falando que o bullying começa não na escola mesmo, mas já vem de um processo bem mais longo.

Ester: Acho que a gente pode começar perguntando tipo, o que que traz o bullying?

Rodolfo: Ah sim! E depois a gente vai meio que respondendo as perguntas assim.

Ester: Isso! Porque é mais fácil.

Ester: Bom, a gente pode falar da família, assim...

Rodolfo: Da estrutura, né?! Da educação. Acho que pode falar da fragilidade social também que influencia na família que é desestruturada tanto economicamente ela sofre algum tipo de (Ester interrompe)

Ester: Até familia que tem tipo, só o pai ou a mãe tipo, não dá suporte, às vezes a criança desconta isso em outra.

Rodolfo: Talvez o bullying seja uma forma de suprir uma falta...

Ester: Sim!

Rodolfo: 0 que ela sente.

Ester: Tipo, pra mim o bullying é assim, a pessoa que pratica o bullying acho que é uma carência assim, uma coisa psicológica mesmo. Aí ela supre a partir disso

Rodolfo: Então, como é que a gente vai falar isso? Vamos falar então que a violência pode ser uma consequência de uma carência mesmo?

Ester: Aham. Mas eu acho melhor colocar isso no desenvolvimento, sabe?!

Rodolfo: Sim! Tem que ter quinhentas palavras, né?!

Ester: É! Tipo assim, "creation" será que serve pra criação?

Rodolfo: Deixa eu pensar! Acredito que sim!
}

Movimentos de colaboração resultam em um processo de ajuda mútua em que um dos parceiros suscita a reflexão do outro, e, dessa forma, um parceiro é levado a escrever sob suas próprias perspectivas e questionamentos e sob as ideias do outro (FILIPETO, 2019). Bolzan (2015) afirma que os textos produzidos por alunos que colaboram mais uns com os outros, em que há respeito mútuo, são geralmente mais organizados, argumentativos e críticos.

No próximo exemplo, da interação estabelecida pela dupla 4, as alunas cooperam na construção temática e na organização textual. Ambas interagem de forma cooperativa, aceitando as opiniões de forma produtiva. Clarice propõe uma organização que enfatiza a definição de bullying, as causas, uma variação e uma proposta de intervenção, além de expressar uma preocupação em 
terminar a tarefa "tem que encher - são muitos parágrafos". Maria, concorda, foca na transposição das ideias na língua alvo "Deixa eu colocar. Como é que escreve?" e faz questionamentos para refletir sobre o cunho social do bullying, que naquele momento estava sendo deixado de lado, em favor da forma textual.

\section{Dupla 4}

Clarice: é, tipo assim, a gente coloca lá a definição, o quê que é, o que causou, uma variação que é o cyberbullying, porque a gente tem que encher, porque são muitos parágrafos.

Maria: Ah, não, demorou, demorou! É "causa", é apresentar argumentos contra com base em estatísticas falando sobre o cyberbullying. Deixa eu colocar. Como é que escreve? Como que o bullying está ligado, extremamente ligado com preconceitos sociais tipo isso.. não é só uma brincadeira tipo, ah vou zuar meu colega.. zuar ele por quê? Porque ele é negro? Porque ele é gay? Porque ele é.. tipo isso entendeu? Porque é mulher..?

Clarice: Tá.. isso a gente coloca.. isso ai é de causa e depois a gente coloca umas coisas de propostas.

Maria: Ah, olha aqui, outra coisa que a gente poderia colocar é sobre, tipo assim, a inviabilização das crianças que sofrem bullying com este tipo de coisa, "brincadeira de criança"; "intimidade de amigos"; ou a criança que reclamar, falar que ela está querendo "chamar à atenção".. tipo este tipo e coisa.

Clarice: Sim.. crianças que não são ouvidas pelos pais que acreditam

No excerto abaixo, Maria domina os turnos colocando suas ideias que vão para o papel com a concordância de Clarice que não opina e não se opõe, assumindo um posicionamento de passividade para construir o texto:

Dupla 4

Maria: Mas acho que, tipo assim, a gente vai ter que falar na proposta de intervenção do cyberbullying e do bullying como só quando é brincadeira, mas a gente deveria falar também de agressões, que acontecem bastante. Tipo assim, principalmente com crianças menores, fraga?

Clarice: Tá! Estou ligada!

Maria: A gente podia pegar isso porque no Brasil, o bullying é muito diferente dos Estados Unidos. Tipo, adolescente lá, sofre mais bullying que aqui.

Clarice: Tá

O padrão de interação tutorial está presente no exemplo abaixo, no qual dois alunos analisam a sentença: "It has been a trouble for many years, before the word bullying exists, the insults and the violence between kids had already been present". Ambos tomam os turnos para compreender o tempo verbal a ser utilizado na sentença. Ester assume o papel de tutora para que Rodolfo entenda a função do tempo verbal.

Dupla 2

Rodolfo: ah sim! Acho que pode usar many years, não é melhor não?

Ester: É! tipo assim, antes de ser considerado tipo, antes de existir o bullying, já existia crianças que insultavam as outras.

Rodolfo: uhum, é que o bullying é apenas uma forma de se referenciar hoje em dia

Ester: hum... Ever exists ou always? não, mas eu acho que... Só tipo, depois que, isso não tem muita necessidade não, tipo assim, já tinha crianças insultando.

Rodolfo: Dois verbos no passado?

Ester: porque tipo seria o que fala do passado no passado. 
Rodolfo: ah sim. É que eu nunca vi esse negócio assim não.

Ester: é muito doido!

Rodolfo: presente, que sempre esteve presente, mesmo antes.

$\mathrm{Na}$ interação abaixo, Beatriz assume uma postura autoritária tentando ditar as regras do jogo: ela escreve e Carlos busca as palavras no dicionário. Como ambos são dominantes, o conflito acontece quando Carlos não aceita esse papel:

\author{
Dupla 1: \\ Carlos: É um cenário? \\ Beatriz: É, procura uma palavra que possa funcionar como "recorrente". \\ Carlos: Repeating them \\ Beatriz: Não ficou legal, olha outra. \\ Carlos: Não! Usa assim! \\ Beatriz: Não Carlos, em cima... Não... Carlos! \\ Beatriz: A primeira frase ficou OK, certo? \\ Beatriz: Eu queria colocar uma palavra tipo... denunciar, sabe? Ah, the victims are too afraid \\ to tell... too afraid to tell. Aí eu quero falar de outras pessoas, pessoas que veem, mas que \\ não contam \\ Carlos: Você pode escrever exatamente isso, pessoas que veem, mas que não contam, \\ não? \\ Beatriz: Mas isso não pode ser incluso aqui não? Não estamos falando só das vítimas que \\ não conseguem... too afraid... to do so... tá melhor assim? Pode, não pode? \\ Carlos: To do it, fica melhor, não? \\ Beatriz: To do it, é, vai ficar tão feio. Mas tá... porque tipo, it, deixa. É, ficou feio, não gostei \\ Carlos: Ficou feio? \\ Beatriz: Aqui não é melhor um aposto? \\ Carlos: É, então acaba de resumir a próxima frase toda \\ Beatriz: Ah... \\ Carlos: Aquela que a gente tinha escrito \\ Beatriz: Era a intenção!
}

Nesse estudo, percebemos que todas as duplas passaram pelos padrões de interação, se beneficiaram da discussão para a execução da tarefa, corroborando os estudos de Bolzan (2015). No entanto, em momentos em que um dos componentes das duplas assumia papéis de dominância, de autoritarismo, ou de total discordância ou não aceitação das ideias do outro, a produção textual era prejudicada.

\title{
Considerações finais
}

Esta pesquisa analisou quantitativamente os dados das produções de texto escritos em coautoria, através da análise do que ocorre no processo interacional e trouxe achados interessantes à medida que se concentrou nas produções colaborativas. O software Iramuteq e a análise da construção temática dos textos propostas por Boccia et al. (2013) permitiram o uso de diferentes recursos para a análise textual na coletividade. Eles trazem contribuições para a compreensão das representações 
sociais do grupo de alunos do Ensino Médio Técnico sobre um dos problemas que eles vivenciam no contexto escolar.

A proposta de ensino demonstra que alunos em pares, em tarefas de produção escrita colaborativa, escreveram textos inteligíveis, organizados e, em certa medida, coesos, além de promoverem a autonomia dos alunos. A natureza do conhecimento que os alunos constroem varia de conhecimento pessoal, científico, linguístico a conhecimentos originários de dentro e de fora do contexto escolar que funcionam como ferramentas simbólicas para o processo de andamento coletivo e de aprendizagem mais consciente.

A aparência das estruturas de participação e/ou interação revela que os alunos convidam explicitamente os colegas à reflexão e para a ação dependendo da relação de poder estabelecida e de suas personalidades em termos de atitudes em relação à colaboração, cooperação ou dominância. Os resultados corroboram o estudo de Filipeto $(2019$, p. 149) que propõe ocupar o tempo da escrita com a discussão em pares para "imprimir uma maior produtividade e criatividade geradora de novos conflitos, personagens, acontecimentos" ao produto final.

Os padrões de interação estabelecidos pelos pares foram relevantes para o processo da escrita criativa e colaborativa e parecem ter instigado à reflexão, à geração de ideias e conflitos, e à promoção de reciprocidade e momentos para o aprendizado do respeito mútuo, da tolerância e do senso de cidadania. Filipeto (2019) atribui o sucesso das atividades colaborativas à necessidade de os alunos refletirem, verbalizarem seus pensamentos observando seus modos de pensar e escrever, além de considerar os de seus parceiros.

\footnotetext{
Para "convencer" o outro sobre a necessidade de se escrever $x$ ou $y$, é necessário apresentar argumentos. Estes argumentos podem conter importantes reflexões metalinguísticas e, ao mesmo tempo, explicitar o modo como pensam quando propõem alterações para o que será escrito ou para o que já foi escrito (FILIPETO, 2019, p. 149).
}

A investigação tem relevância para as áreas de Educação, Linguística e Linguística de Corpus, uma vez que traz uma proposta metodológica de ensino por meio do processamento de textos. Este estudo é uma pequena amostra do potencial do Iramuteq, que viabiliza o mapeamento dos itens lexicais e permite a interpretação de corpora maiores, sem perder o contexto de uso dos itens. Este estudo pode ser replicado em comparação a corpus de referência, possibilitando a integração das análises quantitativas e qualitativas e trazendo objetividade às interpretações dadas ao conteúdo dos textos.

\section{Referências}


ALMEIDA ZEQUINÃO, M.; MEDEIROS, P.; PEREIRA, B.; CARDOSO, F. L. Bullying escolar: um fenômeno multifacetado. Educação e Pesquisa, Universidade de São Paulo. vol. 42, núm. 1, 2016, p. 181-198. Disponível em: <https://www.redalyc.org/pdf/298/29844947013.pdf> Acesso em 03/08/2020. https://doi.org/10.1590/S1517-9702201603138354

BALLINGER, S. Towards a cross-linguistic pedagogy: Biliteracy and reciprocal learning strategies in French immersion. Journal of Immersion and Content-Based Language Education, v. 1, n 1, 2013, p.131-148. https://doi.org/10.1075/jicb.1.1.06bal

BARDIN, L. Análise de Conteúdo. Tradução de Luís Antero Reta e Augusto Pinheiro. Lisboa, Portugal; Edições 70, LDA; 2009.

BERBER-SARDINHA, T. Lingüística de Corpus: histórico e problemática. D.E.L.T.A., v. 16, n. 2, 2000, p. 323-367.

BOCCIA, C.; BRAIN, V.; DORADO, L. FARÍAS, A.; GAUNA, B.; HASSAN, S.; PERERA DE SARAVIA, G. Working with texts in the EFL classroom. 1. ed. Mendoza: Editorial de la Universidad Nacional de Cuyo, EDIUNC, 2013. $176 \mathrm{p}$.

BOLZAN, D. B. Colaboração em produção escrita e percepção dos aprendizes em relação à pratica de revisão por pares. Trabalho apresentado no XI CBLA: Linguística Aplicada para além das fronteiras. 14 a 17 de julho de 2015. UFMS. Campo Grande MS.

BOLZAN, D. B. Colaboração na produção escrita em segunda língua: uma proposta de revisão por pares para a aula de Língua Inglesa em uma escola com Currículo Bilíngue. Tese de Doutorado. Universidade Federal do Rio Grande do Sul, Instituto de Letras, Programa de Pós-Graduação em Letras, Porto Alegre, BR-RS, 2016. $219 f$.

CAMARGO, B. V.; JUSTUS, A. M. Um Software Gratuito para Análise de Dados Textuais. Temas em Psicologia, 2013, v. 21, n. 2, p. 513-518. http://dx.doi.org/10.9788/TP2013.2-16

DILLENBOURG, P., BAKER, M., BLAYE, A. \& O'MALLEY, C.(1996) The evolution of research on collaborative learning. In E. Spada \& P. Reiman (Eds) Learning in Humans and Machine: Towards an interdisciplinary learning science. (Pp. 189-211). Oxford: Elsevier.

FELIPETO, S. C. S. Escrita colaborativa e individual em sala de aula: uma análise de textos escritos por alunos do ensino fundamental. Alfa, rev. linguíst. São José Rio Preto, v. 63, n. 1, São Paulo: Jan./Mar, 2019, p. 141-160. https://doi.org/10.1590/1981-5794-1904-6 
FERNANDES, B. Manual Iramuteq. Tradução Livre do Manual original de Lucie Loubère e Pierre Ratinaud disponível em: http://www.iramuteq.org/documentation/fichiers/documentation_19_02_2014.pdf $\quad$ Acesso em 06/08/2020.

LANKSHEAR, C., BIGUM, C. et al. Digital Rhetorics: Literacies and Technologies in Education - Current Practices and Future Directions. 3 v. Project Report. Children's Literacy National Projects. Brisbane: QUT/DEETYA, 1997.

LARSEN-FREEMAN, D. Chaos/complexity science and second language acquisition. Annual Review of Applied Linguistics, n. 15, June, 1997, p. 141-165.

LEFFA, V. O ensino das línguas na perspectiva do letramento crítico. Palestra de abertura do VI Encontro de Professores de Línguas Estrangeiras: Formação Docente de Professores de Línguas Estrangeiras: trajetórias e perspectivas no ensino, pesquisa e extensão, 2011.

LUCCHESI, C. L. Introdução a Teoria dos Grafos. Instituto de Matemática Pura e Aplicada. Rio de Jnaeiro, 1979.

MCCARTEN, J. Teaching vocabulary: Lessons from the Corpus, Lessons for the classroom. Cambridge, Cambridge University Press, 2007.

MERCER, N. The guided construction of knowledge. Clevedon, UK: Multilingual Matters, 1992, 135p.

NASCIMENTO, A. R. A.; MENANDRO, P. R. M. Análise lexical e análise de conteúdo: Uma proposta de utilização conjugada. Estudos e Pesquisas em Psicologia, v. 6, n. 2, 2006, p. 72-88.

OLIVEIRA, S. B. Produção escrita colaborativa: o olhar de aprendizes da língua inglesa sobre a arte. FóRUM LINGUÍSTICO. Programa de Pós-Graduação em Linguística. UFSC, Florianópolis, v. 14, n. 2 , abr. / jun., 2017, p. 2152-2172. doi: http://dx.doi.org/10.5007/1984 - 8412.2017v14n2p2152

PAIVA, V. L. M. O.; FIGUEIREDO, F.Q. O ensino significativo de gramática em aulas de língua inglesa. In: PAIVA, V.L.M.O. (Org.). Práticas de ensino e aprendizagem de inglês com foco na autonomia. Belo Horizonte: Faculdade de Letras da UFMG, 2005. p. 173-188.

REINERT, M. ALCESTE, une méthodologie d'analyse des données textuelles et une application: Aurélia de G. de Nerval. Bulletin de Méthodologie Sociologique, v. 28, 1990, p. 24-54. 
SHEHADEH, A. Effects and student perceptions of collaborative writing in L2. Journal of Second Language Writing 20 (2011) 286-305. Available online at www.sciencedirect.com

SOUZA, A. P.; ROSSO, A. J. Mediação e zona de desenvolvimento proximal (zdp): entre pensamentos e práticas docentes. Esteris... X Congresso Nacional de Educação - EDUCERE. Pontifícia Universidade Católica do Paraná. CURITIBA, 2011, p. 5894-5906.

STREET, B. V. Letramentos sociais: abordagens críticas do letramento no desenvolvimento, na etnografia e na educação. Trad.: Marcos Bagno. São Paulo: Parábola Editorial, 2014. 240p.

STORCH, N. Collaborative writing: Product, process, and students' reflections. Journal of Second Language Writing. V. 14, 2005, p. 153-173. Disponível em: https://eric.ed.gov/?id=EJ724392 Doi: http://dx.doi.org/10.1016/j.jslw.2005.05.002

STORCH, N, The nature of pair interaction: Learners' interaction in an ESL class its nature and impact on grammatical development. Saarbrücken, Germany, VDM Verlag, 2009.

STORCH, N. Collaborative Writing in L2 Classrooms. Bristol, UK: Multilingual Matters, 2013.

SWAIN, M. Talking-it through: Languaging as a source of learning. In: BATSTONE, R. (Ed.), Sociocognitive perspectives on language use/learning. Oxford: Oxford University Press, 2010, p. 112130.

SWAIN; M.; LAPKIN, S. Focus on form through collaborative dialogue: exploring task effects. In: BYGATE, M.; SKEHAN, P.; SWAIN, M. Researching pedagogic tasks: second language learning, teaching and testing. London: Longman, 2001, p. 98-118.

VYGOTSKY, L. S. A formação social da mente: o desenvolvimento dos processos psicológicos superiores. 4.ed. São Paulo: Martins Fontes, 1991.

Data de submissão: 06/08/2020. Data de aprovação: 23/10/2020. 